\title{
Zakah in a Complex World
}

\author{
Diyah Putriani \\ Universitas Gadjah Mada
}

Gairuzazmi Mat Ghani, Mira Kartiwi

International Islamic University Malaysia

Paper to be presented at the $4^{\text {th }}$ International Conference of Zakat (ICONZ)

7-8 October 2020, Surabaya, Indonesia

\begin{abstract}
The Covid-19 pandemic hits the world economy. On July 2020, some countries have plunged into recession. The prescription from the perspective of Islamic economics and finance need to be formulated. The application conventional methodology like survey or any types of regression will not able to examine the dynamic changes on the economyduring the occurrence of pandemic and will fail to draw the very long term situation. In this regard, Islamic economics needs to move forward to utilize the advancement of technology.
\end{abstract}

The use of Agent-based Computational Model (ABM) is one of alternative methodology to develop research in the area of Islamic economics and finance. ABM is a computational study which builds the economy as a complex world, thus, the prescription for economic crisis based on Islamic views can be formulated.

This research has two objectives, i.e., (a) to review on how ABM has developed research in the area of Islamic economics and finance, $(b)$ to provide an example on how the use of ABM to develop a model on how zakah may minimize level of Gini index under interest based system.

This research finds two main points. First, the number of ABM research in Islamic economics are limited, some of which are still at the development stage of the conceptual framework. Second, the ABM simulation results shows how zakah may minimize level of Gini index. Therefore, this research may be used as one of the references on how to develop and formulate a model in the area of Islamic economic and finance.

Keywords: Zakah, Gini Index, Interest based system, Agent-based Computational Model, Computational Study

\section{INTRODUCTION}

The economic crisis threatens all countries around the world as the COVID-19 start to spread in December 2019. Government around the world took sudden policies such as social distancing, business closure, and even economic lockdown to minimize the outbreak. As its immediate consequences, aggregate production as well as consumption decreased which lead an increase in the level of unemployment rate.
The economic stimulus package has been announced in order to minimize the bigger impact of economic downturn. One of the packages is in the form of loans.

A work studied by Freedman et.al (2010), however, suggests that the stimulus package may cause debt accumulation and as a result will have negative impact on the economy in the long run. Even Cogan \& Taylor (2010) show that the stimulus package have no material effect on the economic growth. In other words, the 
facility of stimulus package particularly in the form of interest-based loans may cause a debt trap for the creditor in the long run which later triggers a negative effect on the economy.

Islamic financial system is argued to be the solution to prevent the negative impact of loans on the economy in the long run. The main feature of Islamic financial system is interest free lending. It implies that Islamic economics and finance needs to contribute to solve this problem. Therefore, the prescription on the negative impact of loans on the economy based on Islamic point of view needs to be developed.

The application conventional methodology like survey or any types of regression will not able to examine the dynamic changes on the economy during the occurrence of pandemic and fail to draw the very long term situation. In this regard, Islamic economics needs to move forward to utilize the advancement of technology. In response to this problem, there is a need to conduct research from different angles. One such class of model that could achieve this objective is the agent-based computational model (ABM).

There are two reasons to apply $\mathrm{ABM}$ in this research. First, the nature of financial system is complex hence it needs to conduct research which involves transaction amongst households, firms and banks. Many significant studies suggest to apply agent-based computational model (ABM) to cover complex interactions amongst the economic agents (Arthur 1994, 1999, 2013; Arthur, Durlauf, and Lane 1997; Oh, 2015). Furthermore, the growing complexity and interconnectedness of financial systems suggest that the model constructed should include collective intelligence and exhibit the emergent behavior of the agents at the macro level (El-Masri, 2015). Second, the application of $A B M$ in this research is to bring the use of artificial intelligence to develop research in the area of Islamic economics and finance.
Considering these problem, this research is proposed to (a) review on how ABM has developed research in the area of Islamic economics and finance, and (b) to provide an example on how zakah may minimize the level of Gini index under interest based system.

This study differs from previous literature in three directions. First, this research is potentially to be the early work on the development of Islamic economics and finance using $\mathrm{ABM}$ framework. Second, while prior studies employ the traditional qualitative approach and took empirical cases, this study introduce an exploratory approach and applies simulation as a research method, i.e. the Agent-based Computational Model $(\mathrm{ABM})$. We use $\mathrm{ABM}$ in order to allow the use of computational study as an alternative method to develop research in Islamic economics. Third, this study reviews prior ABM paper particularly in the area of Islamic economics and finance.

This study is divided into six parts. The first part introduces the research and includes the research gap and contribution. The second part explains the theory of ABM. The third part explains the selected research method. The fourth section examines the analysis, while the conclusion and policies recommendation are elaborated in the fifth section. Finally, some ideas for future research is explained in the sixth section.

\section{AGENT-BASED COMPUTATIONAL MODEL}

The application of ABM is not only limited to economics, but also employed in other sciences, such as agriculture, archaeology, ecology, anthropology, crime analysis, energy analysis, environmental planning and policy, epidemiology (infectious diseases), biomedical research, market analysis, healthcare, evacuation, social 
psychology, social networks, and even air traffic control (Macal and North 2014).

Agent-based modeling is a computational approach used to build a model of a complex system. Such a system consists of heterogenous interacting agents which have goals within an environment; the interaction is based on a set of rules. Therefore, a computational approach can be viewed as an object-oriented model, i.e. composed of units of agents rather than variables (Oh, 2015).

The genesis of the computational approach can be traced back to the work of (Neumann, 1951) on the logical theory of automata. It should be underlined that Neumann's (1951) was the first study to build a model of artificial life; however, the origin of ABM is rooted in the work of (Schelling, 1971) on dynamic segregation. Schelling's (1971) model shows that agents (individuals) are happy to live in a society of agents with different races, but they still want to segregate society over time and attempt to be with the same race.

In the area of economics, $\mathrm{ABM}$ is defined as the computational study of artificial economies, modelled as evolving systems of autonomous interacting agents. The artificial economy evolves over time as its constituent agents repeatedly interact with each other and learn from their interactions. The "agent" in ABM refers broadly to bundled data and behavioral methods representing an entity constituting part of a computationally constructed world. Possible agents may include individuals, social groupings, and institutions, biological and physical entities. Moreover, agents can be composed of other agents, thus permitting hierarchical constructions. For example, a firm might be composed of workers and managers (Tesfatsion, 2011).

The main advantage of $A B M$ is its ability to observe the dynamics of the system and hence be able to answer the questions of how and why. For example, how equilibrium is achieved, if it is achieved at all, or how is it that a system is in disequilibrium for a long period of time. $\mathrm{ABM}$ also has the ability to study complex interdependent systems. Examples include the ability to model multiple markets, interactions between markets and policies, and a wide variety of heterogeneous actors and institutions (Barr, Tassier, \& Ussher, 2011).

Tesfatsion and Judd (2006) further elucidate that $\mathrm{ABM}$ allows the agents to drive the event after the initial parameters are determined. Therefore, ABM aims to monitor and investigate whether some form of equilibrium emerges over time. In other words, the goal of ABM research is to understand the system entirely works, i.e., all possible equilibrium as well as the interconnections amongst the variables. Furthermore, the application of ABM is to facilitate communication amongst the agents using message and to design the agents with relatively more autonomy.

Chan and Steiglitz (2008) classify three groups of $\mathrm{ABM}$ in economics. The first type is the ABM, which combines theoretical economic theory and machine learning (or other computational techniques). The model of overlapping generation (OLD) is an example of the first category and has been applied as the foundation to develop ABM in economics.

The second type is the agent-based model in economics which replicates the real world and involves large simulations of the real economy. The EURACE model is an example of the second group of ABM. According to Lengnick (2013), the EURACE model is the largest and the most complete example of ABM which attempts to model the European economic system and was initiated by a group of economists and computer scientists in 2009. Eurace is run by using complicated parallel computing groups and high quality computers as it involves a huge number of agents. Nevertheless, the model is too complicated to be replicated or developed. 
In 2011, the EURACE model was extended and simplified by Dawid et al. (2011) and is now known as the EURACE@Unibi model, with the aim to provide economic policy analysis.

The third type of model is based on a number of stylized facts about the real world. Compared to the second type, this model involves a relatively small number of different agents and sets of simple rules and does not try to produce a replica, but instead attempts to build a simple minimal world (Oh, 2015). In other words, it does not comprehensively replicate the whole economy. Therefore, the third model can be executed on a personal computer. This research is categorized as the third type of ABM.

The interest in ABM simulation in social sciences has increased over the last two decades. For instance, the Complex Systems Social Sciences Association (CSSSA) and the World Congress on Social Simulation (WCSS) have held conferences using complex system methods as well as $\mathrm{ABM}$ in the area of social sciences. In the last few years, the Eastern Economics Association, the American Association of Geographers (AAG), Marketing Science, and the American Education Research Association (AERA), have conducted programs on the intersection of social sciences and ABM. In this regard, economics has become an area that has received increased attention from the $\mathrm{ABM}$ community because an economy is composed by heterogeneous economic agents, for instance consumers, producers, and governments. In 1996, the first book about the relationship between ABM and economics was written by Josh Epstein and Robert Axtell, who created a world called SugarScape (Wilensky \& Rand 2015). In other words, the use of ABM in research activities has been widely accepted.

\section{METHODOLOGY}

Voluminous articles have been published in the area of Islamic economics and finance. Majority of these articles apply qualitative approach and empirical study. In this research, the author provides a literature review of agent-based computational model $(\mathrm{ABM})$ and its technical example on the use of ABM in the area of Islamic economics and finance through a conceptual and theoretical argument rather than empirical research.

\section{DISCUSSION}

\section{Islamic Economic Models: History and Development}

There is limited published research on $\mathrm{ABM}$ in the area of Islamic economics. Interestingly, all ABM simulations in this area and that of finance have been run using NetLogo, developed by Wilensky and Rand (2015). According to the author's observations, the initial publications on $\mathrm{ABM}$ in the Islamic economics area can be traced back in the last decade to the works of Al-Suwailem $(2008,2011)$.

Recently, research into $\mathrm{ABM}$ in Islamic economics has been further developed by the establishment of the Islamic financial engineering (IFE) laboratorium, sponsored by Islamic Development Banks at the Mohammadia School of Engineering in Morocco. The laboratorium was established in 2015, with one of the main members of the advisory committee being Al-Suwailem, who became a pioneer of $\mathrm{ABM}$ development in Islamic economics and finance.

The main objective of the establishment the IFE laboratorium establishment was to integrate contemporary technology and the foundation of Islamic economics and finance. Therefore, the laboratorium may enhance the financial industry and produce financial engineers in Islamic finance. 
Eight studies were produced by the IFE in 2016 and 2017; three of these by (Bensaid et al. 2017), Boularhmane and Souissi (2016) and Aaminou and Aboulaich (2016) are previous studies which build an $\mathrm{ABM}$ to observe dynamic changes in the economy.

Bensaid et al. (2017) build an ABM to observe the efficiency of the cooperative system in Islamic microfinance. The system has four to six members; the results of the simulation show that higher bankruptcy occurs in the system with no cooperation (61.58 percent) compared to the cooperative system (31.58 percent). In addition, wealth is more equally distributed, and the Gini index has a lower coefficient in the cooperative system than that with no cooperation.

Boularhmane and Souissi (2016) extends the model of Al-Suwailem (2008) i.e. by replacing the household agents with firms. Therefore, the study is able to introduce profit and loss sharing (PLS) as one of the financing schemes. The main scenario of the model is a comparison of the performance of the economy if different types of financing is introduced and no banks exist. In other words, financing is disbursed from surplus companies to deficit companies. There are three types of financing schemes: PLS, markup and interest-based financing. During the simulation, only one mode of financing was set up; for instance if the simulation was run to observe the impact of PLS on economic performance, then markup and interestbased financing were excluded. The primary results show that both PLS and markup-based financing promote economic stability. On the other hand, interest-based lending creates great instability in the economy.

In addition, Aaminou and Aboulaich (2016) create a model dynamic of both Islamic and conventional banking markets to observe whether issue of ethics were the main element when customers made investment decisions. Ethics in this model is represented by the application of CSR. The results show that the application of CSR is considered as an important element by customers when making such decisions. Promotion is effectively published through social media.

The other five studies produced by the IFE laboratory still need to be developed as they are categorized as conceptual research and the models have not been run for simulation. These five studies are by Bourhime and Tkiouat (2016), that explain that microfinance is a complex system in nature; Elhachami and Tkiouat (2016), who model consumer goods; Naciri and Tkiouat (2015, 2016), who review the use of ABM in economics; and Mohamed and Khadija (2015), who attempt to model the Moroccan economy.

At this point, it can be concluded that the number of ABM research in Islamic economics are limited, some of which are still at the development stage of the conceptual framework. Therefore, there is a big gap in current ABM research with regard to the building of a model in the area of Islamic economics and finance.

\section{Developing an Islamic Economy in a Complex World}

1) Overview, Design and Details (ODD) Protocol

ABM simulation has been widely accepted as an alternative tool in many study areas which deal with complex systems, especially in the area of economics and finance. Therefore, a group of modelers built a standard protocol for ABM i.e., ODD protocol. In other words, ODD protocol is a guideline to develop an ABM.

The first standard protocol was developed by Grimm et al. (2006) and involved 28 modelers to test it. It consists of three elements, i.e. overview, design concepts and details (or ODD). The three elements of ODD were categorized into seven parts, 
namely (1) purpose, (2) state variables and scales, (3) process overview and scheduling, (4) design concepts, (5) initialization, (6) input and (7) sub models.

In 2010, Grimm et al. (2010) revised the definition of each element of the first version of ODD, as well as the components of the protocols, especially in the element design concept. Therefore, the old version of 2006 was replaced by the newest version of the ODD protocol introduced in 2010. The differences between ODD 2006 and 2010 are shown in Table (4.1).

Table 1. Overview, Design Concept and Details (ODD) ABM Protocol

\begin{tabular}{lll}
\hline Protocol & ODD (2006) & ODD (2010) \\
\hline Overview & 1. Purpose & 1. Purpose \\
& 2. State variable and scale & 2. State variable and scale \\
& 3. Process overview and & 3. Process overview and \\
scheduling & scheduling \\
\hline Design Concept & 4. Design concept & 4. Design concept \\
& - Emergence & - Basic principles \\
& - Adaptation & - Emergence \\
& - Fitness & - Adaption \\
& - Prediction & - Objectives \\
& - Sensing & - Learning \\
& - Interaction & - Prediction \\
& - Stochasticity & - Sensing \\
& - Collectives & - Interaction \\
& - Observation & - Stochasticity \\
& & - Collectives \\
& & - Observation \\
\hline Details & 5. Initialization & 5.Initialization \\
& 6. Input & 6.Input \\
& 7. Submodels & 7.Submodels \\
\hline
\end{tabular}

Source: Grimm et al. (2010)

2) Employing a Software: NetLogo

To run the simulation, this study uses a software package called as NetLogo@. Netlogo(C) was developed by Prof. Uri Wilensky at Northwestern University (Wilensky 2003). As aforementioned that all ABM simulations in the area of Islamic economics and finance have been run using NetLogo. This software indeed is is widely used both for research and teaching tool as it includes a modeling environment apt for a simulation complex system and social phenomena (Freeman 2005).
3) Developing An ABM

Typically, ABMs can be built to emphasize particular features of the world or particular mechanisms of interaction. Choosing which features and mechanisms to select and trialing alternative selections is part of the art of modeling complex systems (Wilensky and Rand, 2015). Two fundamental elements of ABM design principles includes (a) starting with the simplest set of agents and its rules of behavior, and (b) designing the complete set. The ABM model, therefore, should simplify aspects of the world, and is aimed at answering specific questions. By keeping the model as simple as possible 
makes it easy to understand and to verify. A process of verification comprises steps to guarantee that the simulated model applies exactly its target conceptual model. In other words, there are 2 steps to build an $\mathrm{ABM}$, i.e. first, build a conceptual model and second, build the simulated model.

Recall that this research is basically aimed to provide an example on how the use of ABM to develop a model in the area of Islamic economics and finance. In other words, this research explains the technical part on the application of ABM in Islamic economics and finance. Thus, the development of a conceptual model and simulated model in this research is based on authors' previous work (Putriani, Ghani and Kartiwi (2019a and 2020).

\section{4) Developing A Conceptual Model}

To construct an ABM, a researcher may firstly refer to previous $A B M$ work. In this regards, the development of ABM does not necessary build a model from the scratch. For instance, this research develop a model from Al-Suwailem (2008) by introducing three sectors in the model, i.e. firm market, credit market and labor market. Therefore, the process scheduling may follow AlSuwailem's (2008) previous work with some modifications, e.g., adding zakah variable. The process overview and scheduling in each period can be explained as follows:

a) The household sector is assumed to have consumption plan based on their income and saving allocation. Those who have status as employee will get income. In this case, if households plan to save some of their income, they may save it in the bank and will get additional wealth in the form of interest. In the other hand, if the household wants to consume but their income is not enough, they can propose a loan and have to pay back their loan monthly.

b) As initial study, the addition of zakah in the model is treated as exogenous variable. The indebted households who get default will receive zakah equals to the minimum consumption of respected households.

c) Similar to households, the firms is assumed to have targeted number of product as well as number of workers who will be employed in each period. If the financial resource cannot cover the production cost, the firm will ask financing.

d) In the production process, each firm will decide its product's price. Each firm will receive either profit or loss.

e) The instalment phase starts. All indebted household and firm need to payback their loan. If they cannot payback, they will be reset, i.e. introducing new firms or households in the system. Therefore, the total number of the agents will not change throughout the simulation.

f) The change in the level of Gini index occurs when the depositor receives monthly interest rate (on saving) paid by the bank. In other words, the total wealth of the depositors increases and hence will chane in the distribution of wealth amongst the economic agents in the economy.

By conducting these six steps of scheduling in the simulation, the result of simulation will show the difference or similarities on wealth distribution under economy without and with zakah. 
5) Determining the Parameters

Ideally, the determination of parameters is based on the result of empirical data calibration. However, a researcher may determine the model parameter by referring previous research with some modification. In this research details of intial condition and parameters in this research refers to the work of Assenza et.al (2015).

Table 2. Initial Condition and Parameters

\begin{tabular}{lc}
\hline Parameters & Initial Condition \\
\hline Number of periods & 3000 \\
\hline Number of workers & 3000 \\
\hline Number of firms & 200 \\
\hline Marginal productivity of labour & 0.5 \\
\hline Marginal productivity of capital & $1 / 3$ \\
\hline Probability of investing & 0.25 \\
\hline Wage & 1 \\
\hline Liquidity of firm & 10 \\
\hline Capital & 10 \\
\hline Production & 5 \\
\hline Equity of bank & 3000 \\
\hline Wealth of households & 2 \\
\hline Interest rate on credit & $6 \%$ p.a \\
\hline Interest rate on deposit & $2 \%$ p.a \\
\hline Dividend payout ratio & 0.2 \\
\hline Marginal propensity to consume & 0.05 \\
\hline
\end{tabular}

6) Validating the Model

Validation is a process to ensure whether the simulated model links to and describe some facts in the real world. In other words, validation is not a process to compare the value of empirical and simulated data. The validation process is conducted after the simulation process has finished. The simplest way to conduct validation is to calculate and compare the standard deviation of the simulated model and empirical data. The closer value of standard deviation from the simulated data to empirical data, the more valid of the simulated model.

For example, this research retrieves empirical data from website of the FED of St.Luis with time spans from 1947 quarter 1 to 2018 quarter 4. Both simulated and empirical data are detrended using Hodrick-Prescott (HP) filter procedures. Result of the simulated data compared to the empirical data is shown in table (4.3). The standard deviation result shows similar value between data generated from the simulation and empirical data, hence the ABM model in this research is valid.

Table 3. Standard Deviation of Empirical and Simulation Data

\begin{tabular}{llr}
\hline Variables & & St.Deviation \\
\hline \multirow{2}{*}{ GDP } & Empirical & 2.91702 \\
\cline { 2 - 3 } & Simulation & 4.98996 \\
\hline \multirow{2}{*}{ Consumption } & Empirical & 2.54959 \\
\cline { 2 - 3 } Investment & Simulation & 3.47209 \\
\hline \multirow{2}{*}{ Unemployment } & Empirical & 17.15384 \\
\cline { 2 - 3 } & Simulation & 16.43632 \\
\cline { 2 - 3 } & Simpirical & 1.65241 \\
\hline
\end{tabular}

Source: Authors' calculation

7) Interpreting the Result

A researcher needs to run the model multiple times, i.e., at least 30 times. 
Subsequently, the simulated data can be tabulated and plot it into the graph. Figure (4.1) shows the final simulation result. It exhibits the difference in the level of Gini index under two scenarios, i.e. zakah does and does not exist in the system. That is, in the long run, the economy without zakah will experience high inequality, and reversely when zakah is introduced in the system the level of Gini index remains stable. Note that the model without zakah simulate the economy is run fully using loan. In other words, it can be inferred that zakah may reduce the negative impact of loan in the long term and hence, zakah can be used as one of the main tool to overcome the economic crisis.

Figure 1. Summary Comparison of Gini Index Under Two Scenarios

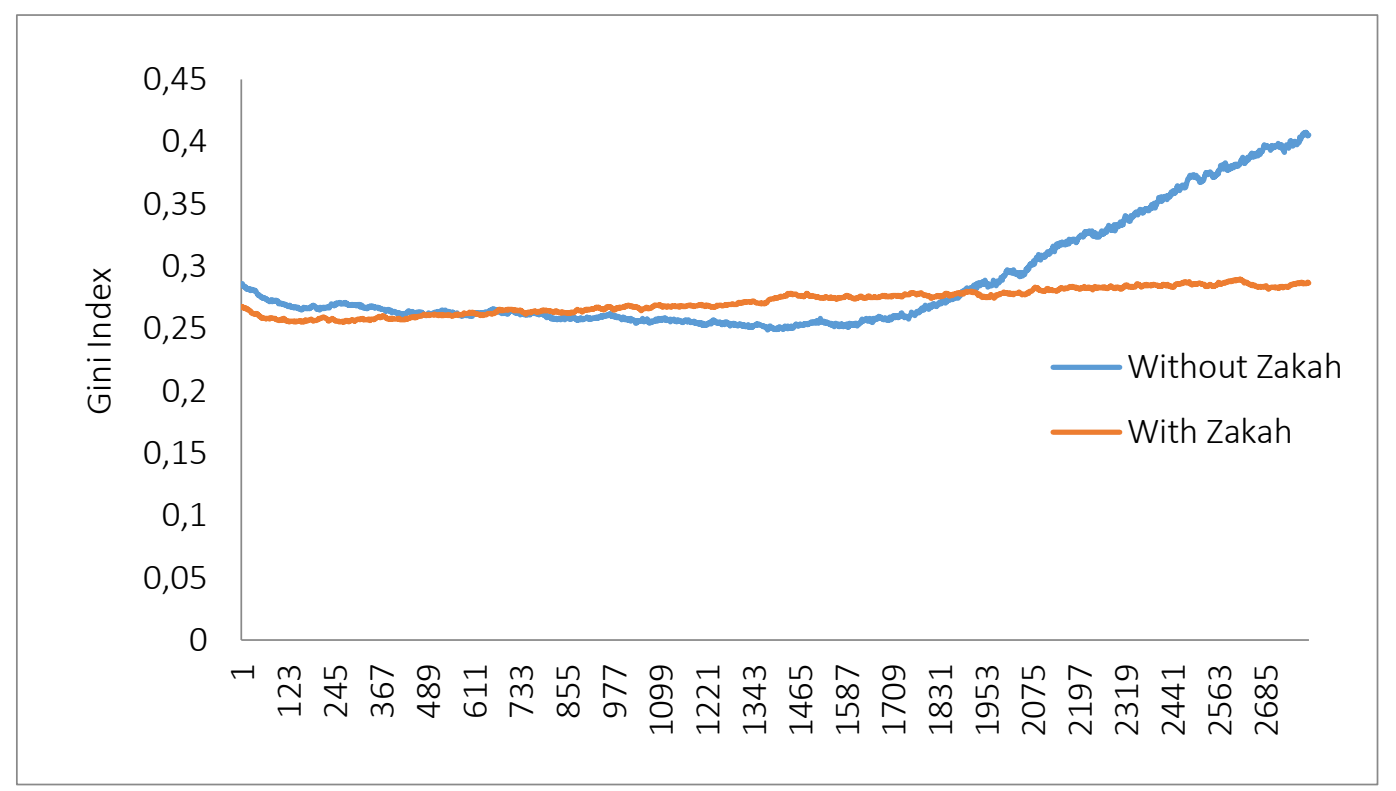

Source: Putriani, Ghani and Kartiwi (2019)

Referring to this result, this research argues that $\mathrm{ABM}$ can be considered as one of a potential tool to develop and construct a model particularly in the area of Islamic economics and finance. In addition, the ability of ABM to build a pure Islamic economy may accommodate other fundamental questions which has not been answered nor examined, for instance a question in this research. By constructing a model of Islamic economy using ABM approach, it is expected that the theory of Islamic economics and finance will be scientifically accepted by mainstream economics.

\section{CONCLUSION}

A research studied by Freedman et.al (2010) and Cogan \& Taylor (2010) show that the stimulus package in the form of loan may cause negative impact on the economy in the long run. Islamic financial system is argued to be the solution to prevent the negative impact of interest based loans in the economy in the long run. Zakah as one of fundamental social security system in Islam should be used to avoid this negative impact. However, there are only little number of studies evaluating by how much zakah may have positive impact on the economy. This is because conventional methodology like survey or any types of regression is not able to examine the research question. Therefore, Islamic 
economics needs to take benefit from the advancement of technology and develop a model of Islamic economy graphically.

This research has shown the example on how the application of computational method using $\mathrm{ABM}$ is able to develop research in the area of Islamic economics research. For instance, a fundamental question on the reduction level of Gini index after zakah enforcement can be examined. In other words, zakah can be used as one of the tools to minimize the negative impact of interest based loans. By constructing a model of Islamic economy using ABM approach, it is expected that the theory of Islamic economics and finance will be scientifically accepted by mainstream economics.

\section{RECOMMENDATION}

The number of ABM research in Islamic economics are limited, some of which are still at the development stage of the conceptual framework. Therefore, there is a big gap in current $\mathrm{ABM}$ research with regard to the building of a model in the area of Islamic economics and finance. Many fundamental questions in this area has not been explained, however, it is not an easy task to formulate and build an Islamic economic model. In addition, the world we are living is basically complex which has interconnection amongst the economic sectors. Thus, it needs an extra effort to develop the model, i.e. engaging with other discipline like computational study. The advancement of technology, thus, should be benefited by the Islamic economics researcher. Technically, it can be done by building a research center or laboratory which focuses on the model development and simulation study in each university. It is expected that the development of Islamic economics and finance research may run effectively.

\section{REFERENCES}

Aaminou, Mohamed Wail, and Abdulaich Rajae. 2016. "Leveraging Ethics to Expand Islamic Banks ' Customer Base: A Fuzzy Agent-Based Modeling Approach.” Asian Journal of Applied Sciences 04(03): 558-74.

Al-Suwailem, Sami. 2008. Complexity Islamic Economics In A Complex World: Explorations in Agent-Based Simulation. Jeddah: King Fahad National Library Cataloging-inPublication Data Islamic Development Bank.

Arthur, W. Brian. 1994. "Inductive Reasoning and Bounded Rationality." The American economic review 84(2): 406-11. http://www.jstor.org/stable/2117868.

1999. "Complexity and the Economy." Science 2(284): 107-9.

\section{Complexity Economics: A} Different Framework for Economic Thought.

Arthur, W. Brian, Steven Durlauf, and David Lane. 1997. "The Economy as an Evolving Complex System II." In eds. W. Brian Arthur, Steven Durlauf, and David Lane. , 1-14.

Bensaid, Khalid et al. 2017. “Agent Based Modeling of Islamic Microfinance with Cooperatives and Takaful System." International Journal of Applied Business and Economic Research 15(5): 737-56.

Boularhmane, Ilham, and Mohamed Amine Souissi. 2016. "Corporate Islamic Financing In A Complex Economy." International Journal of Applied Engineering Research 11(14): 817176.

Bourhime, Sara, and Mohamed Tkiouat. 2016. "Microfinance Overview: From Simple Loans to Complex Systems." Asian Journal of Applied Sciences 04(01): 87-94. 
Chan, Christopher K, and Ken Steiglitz. 2008. Princeton University An AgentBased Model of a Minimal Economy. Princeton.

Dawid, Herbert et al. 2011. The Eurace@Unibi Model: An AgentBased Macroeconomic Model for Economic Policy Analysis. Germany.

El-Masri, Fatena. 2015. "Agent-Based Modelling and Statistical Analysis of Complex System with Applications to Financial Network for Failing Banks." George Mason University.

Elhachami, Khadija, and Mohamed Tkiouat. 2016. "Towards an AgentBased Modeling of the Consumer Goods Market." Asian Journal of Applied Sciences 04(02): 276-85.

Freeman, Tyler R. 2005. "From the Ground up: An Agent-Based Model of Regional Structural Change." University of Saskatchewan. https://www.dropbox.com/s/4r1zw7 pur42hvu1/2005_Freeman_Thesis.p $\mathrm{df} ? \mathrm{dl}=0$.

Grimm, Volker et al. 2006. "A Standard Protocol for Describing IndividualBased and Agent-Based Models." Ecological Modelling 198(1-2): 115-26.

. 2010. "The ODD Protocol: A Review and First Update." Ecological Modelling 221(23): 2760-68.

http://dx.doi.org/10.1016/j.ecolmode 1.2010.08.019.

Lengnick, Matthias. 2013. “Agent-Based Macroeconomics: A Baseline Model." Journal of Economic Behavior and Organization 86: 10220.

http://dx.doi.org/10.1016/j.jebo.2012 .12.021.

Macal, Charles M., and Michael J. North. 2014. "Introductory Tutorial: AgentBased Modeling and Simulation." Proceedings - Winter Simulation
Conference: 6-20.

Mohamed, Tkiouat, and El Hachami Khadija. 2015. "The Agent-Based Modeling of the Macroeconomic Behavior of Sharia-Compliant Companies." In International Congress on Islamic Economics and Finance, Sakarya, 1-19.

Naciri, Nawfal, and Mohamed Tkiouat. 2016. "Economic Agent Based Models : Review." International Journal of Applied Engineering Research 11(8): 5492-5502.

Neumann, John. 1951. 5 The General and Logical Theory of Automata. Oxford: Pergamon Press.

Oh, Young Joon. 2015. “Agent-Based Network Modeling for the 2008 Financial Crisis and the Sluggish Recovery." The University of Texas at Dallas.

Schelling, Thomas C. 1971. "Dynamic Models of Segregation." Journal of Mathematical Sociology 1: 143-86.

Tesfatsion, Leigh. 2011. "Agent-Based Computational Economics: Modelling Economies as Complex Adaptive Systems." Eastern Economic Journal. 37: 40-43.

Tesfatsion, Leigh, and Kenneth L Judd. 2006. Handbook of Computational Economics, Volume 2 Agent-Based Computational Economics. Amsterdam,: Elsevier B.V.

Wilensky, Uri. 2003. "The NetLogo 5.3.1 User Manual." (November): 427.

Wilensky, Uri, and William Rand. 2015. An Introduction to Agent-Based Modeling: Modeling Natural, Social and Engineered Complex System with NetLogo. The MIT Press Massachusetts Institute of Technology. 
Diyah Putriani

Department of Economics, Universitas

Gadjah Mada

diyah.putriani@ugm.ac.id

Gairuzazmi Mat Ghani

Department of Economics, International

Islamic University Malaysia

Mira Kartiwi

Department of Informatics System,

International Islamic University Malaysia 